\title{
Determination of Volatile Compounds from Commiphora myrrha (Nees) Engl. Resin Marketed in Central Sudan by GC/MS
}

\author{
Hatil Hashim EL-Kamali ${ }^{1, ~ *, ~ B a d r ~ O m e r ~ B u r h a m ~}{ }^{2}$, Awatif Abdel Bagi EL-Egami ${ }^{3}$ \\ ${ }^{1}$ Department of Botany, Faculty of Science and Technology, Omdurman Islamic University, Omdurman, Sudan \\ ${ }^{2}$ Department of Chemistry, Faculty of Science, AL-Baha University, AL-Baha, Saudi Arabia \\ ${ }^{3}$ Department of Phytochemistry, Medicinal and Aromatic Plants Research Institute, National Centre for Research, Ministry of Science and \\ Technology, Khartoum, Sudan
}

Email address:

htlkamali@yahoo.com (H. H. EL-Kamali), badrburham@yahoo.com (B. O. Burham), elegami@hotmail.com (A. A. B. EL-Egami)

To cite this article:

Hatil Hashim EL-Kamali, Badr Omer Burham, Awatif Abdel Bagi EL-Egami. Determination of Volatile Compounds from Commiphora myrrha (Nees) Engl. Resin Marketed in Central Sudan by GC/MS. American Journal of BioScience. Vol. 3, No. 4, 2015 , pp. 117-120. doi: 10.11648/j.ajbio.20150304.11

\begin{abstract}
The medicinal properties attributed to resins of this plant in Sudanese traditional medicine prompted us to study the chemical composition of the oil. The GC/MS chromatogram of the oil revealed the presence of 58.86\% monoterpenes and 23.28\% sesquiterpenes. Predominant monoterpenoids were; m-cymene (21.56\%), linalool (7.21\%) and p-mentha-1-en-8-ol $(5.28 \%)$ while the predominant sesquiterpenoids were; alpha-guaiene $(3.55 \%)$ and $\mathrm{C}_{15} \mathrm{H}_{24}(3.23 \%)$.
\end{abstract}

Keywords: Commiphora myrrha, Essential Oil Composition, Resins, Sudan

\section{Introduction}

Continuing our investigations on chemistry of essential oils from aromatic plants used in Sudanese Traditional Medicine [1] - [5], we have analyzed the essential oil of Commiphoramyrrha. The resin is used by the Sudanese local people to treat various ailments.It was masticated as antiseptic. A paint was prepared for skin diseases and pustule complaints. Resins obtained from various other species of Commiphora were used as substitute of C. myrrha. This complicates the characterization of myrrh, because most previous chemical studies reported on the resin were based on commercial material, and not on a product obtained from properly identified trees [6].

The aim of this paper is to present qualitative and quantitative analysis of the oil of this plants species marketed in the central Sudan.

\section{Materials and Methods}

\subsection{Plant Material}

The plant material (resin) used in this study was purchased in April, 2010 from Bahry Market, Khartoum State, Sudan.
Based on the available specimen, the plant material was identified as C. myrrha by one of the author, Prof. H.H ELKamali.

\subsection{Preparation and Isolation of Volatile Component}

The resin sample of $C$. myrrha was subjected to hydrodistillation for $4 \mathrm{~h}$ using a Clevenger - type apparatus. The oil was dried over anhydrous sodium sulfate and stored at $5 \mathrm{C}$ until analysis [7].

\subsection{Gas Chromatographic-Mass Spectrometry (GC/MS)}

GC-MS analyses were performed on a QP-2010 Shimadzu spectrometer instrument. Fused silica capillary column with stationary phase was used: $(50 \%$ phenyl and dimethylpolysiloxane) and (50\% dimethylpolysiloxane), 30 $\mathrm{m}, 0.25 \mathrm{~mm}$ diameter. The analytical conditions were as follows: carrier gas, helium ; injector temperature , $250 \mathrm{C}$; temperature program, $1 \mathrm{~min}$ at $70 \mathrm{C}$ rising to $220 \mathrm{C}$ at a rate of $3 \mathrm{C} / \mathrm{min}$. Individual components were identified by comparison of the retention times and mass spectra provided by Wiley Library in the data system and literature [8]. 


\section{Results and Discussion}

Light yellow volatile oil was obtained by hydrodistillation of dried resin of C. myrrha in $2.1 \%$ yield. Table 1 shows the relative percentages, formula, class type, retention time, mass peaks, base peaks and main fragment ions of the constituents of the C. myrrha resin oil.

Table 1. chemical composition of Commiphora myrrha resin.

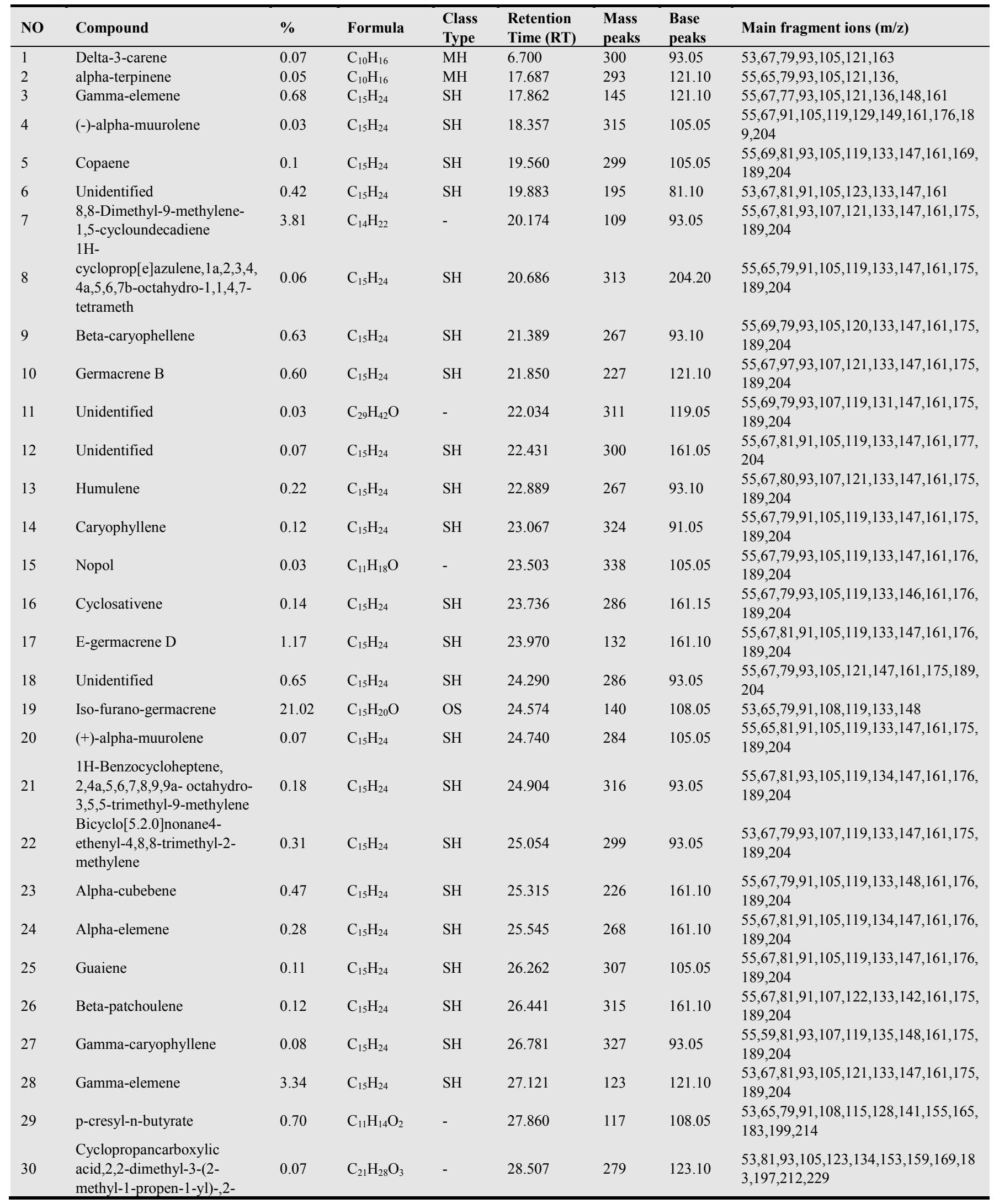




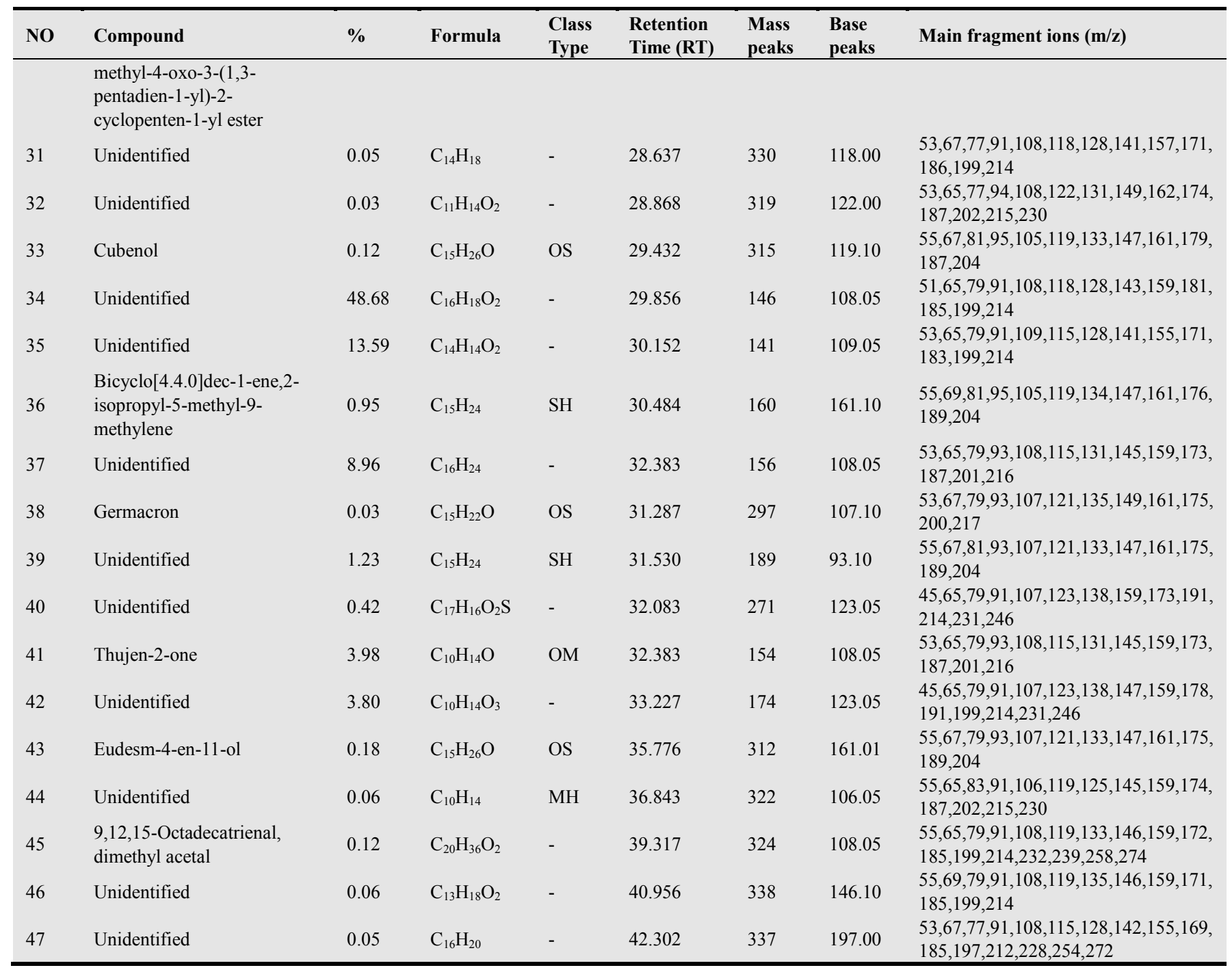

$\mathrm{MH}=$ Monoterpene hydrocarbons; $\mathrm{OM}=$ Oxygenated Monoterpenes;

$\mathrm{SH}=$ Sesquiterpene Hydrocarbons; OS = Oxygenated Sesquiterpenes.

Thirty two components were identified by GC/MS in $C$. myrrha oil, accounting for more than $68 \%$ of the whole oil. The C. myrrha essential oil mainly consists of oxygenated sesquiterpenes (Ca. 21.35\%), followed by sessquiterpene hydrocarbons (Ca. 10.01\%), oxygenated monoterpenes $(2.98 \%)$ and monoterpene hydrocarbons $(0.18 \%)$.

The main components were the $\mathrm{C}_{16} \mathrm{H}_{18} \mathrm{O}_{2}(42.68 \%)$, the oxygenated sesquiterpene, isofurano-germacrene $(21.02 \%)$, $\mathrm{C}_{14} \mathrm{H}_{14} \mathrm{O}_{2}(13.59 \%)$ and 8,8-Dimethyl-1,9-methylene - 1,5cycloundecadiene $(3.81 \%)$. Some other components were only characterized but not identified (Ca. 32\%).

Extracts prepared from C. molmol resins were analyzed by GC/MS. Twenty two terpenoid compounds were identified in the hexane extract of the resin. Among them, 2acetoxyfuranodiene $\quad(9.80 \%)$, furanoeudesma-1,3-diene $8.97 \%$, isofuranogermacrene $6.71 \%$, epicurzerenone $3.64 \%$, 2-methoxyfuranodiene $2.97 \%$ and lindestrene $2.74 \%$ were the main compounds from the myrrha resin, Tamar Ltd). Furanoeudesma-1,3-diene $20.59 \%$, isofuranogermacrene $17.94 \%, \quad$ 2-acetoxyfuranodiene $\quad 8.80 \% \quad, \quad 2-$ methoxyfuranodiene $7.33 \%$ and lindestrene $6.24 \%$ from myrrha resin, Pamir Ltd. [9]. The major constituents of the essential oil identified from the resin of C. myrrha by Mohammed et al., [10] were alpha- elemene, 7-isopropyl1,4-dimethyl-2-azulenol, curzerne, germacra-1(10)7,11-trien15-oic acid and 8,12-epoxy-6-hydroxy-C-lactone. Volatile concentrates from the oleo-gum resin of C. myrrha was isolated by supercritical extraction with carbon dioxide. It is main components, identified and quantified by GC/MS were furanoeudesma-1,3-diene, lindestrene, curzerene and germacrone [11]. Chemical analysis of essential oil from resin of Myrrha shows that the resin is rich in sesquiterpenes and sesquiterpene lactones compounds that possess antiinflammatory and antitumor activity [12].

\section{Conclusion}

Analysis of C. myrrha resin oil in this study is an attempt to gain a better understanding of the secondary metabolite profile of this important valuable plant species. 


\section{Acknowledgement}

We thank Department of Chemistry, Ministry of Science and Technology, Central Laboratory, Khartoum, Sudan, for the GC/MS facilities.

\section{References}

[1] EL-Egami AA, Burham BO and EL-KamaliHH. Essential oil composition of the flowering aerial parts of Sudanese Morettiaphillaeana (Del.) DC.Current Research Journal of Biological Sciences. 2011. 3(2):100-103.

[2] EL-KamaliHHet al.,.Chemical constituents of the volatile oil of Cyperusrotundus L. from Central Sudan.Journal of the Faculty of Science and Technology (JFST). 2011. Issue No. 2.

[3] Burham BO, EL-KamaliHH, EL-Egami AA. Volatile components of the resin of Pistacialentiscus "Mistica" used in Sudanese Traditional Medicine .Journal of Chemical and Pharmaceutical Research. 2011. 3(6):478-482.

[4] EL-kamaliHH, Burham BO, EL-EgamiAA .Analysis of the essential oil from fruits of Croton zambesicusMuel. Arg. Growing in Southern Kordofan, West Sudan. Natural Products Research Bulletin. 2012. 1(1): 1-6.

[5] Ramadan MM, Abdel GaderNN, EL-KamaliHH, GhanemKZ, Farrag AH. Volatile compounds and antioxidant activity of the aromatic herb Anethumgraveolens .Journal of the Arab Society for Medical Research. 2013. 8: 79-88.

[6] Tucker, A.O. Frankincense and Myrrh. Economic Botany. 1986. 40:425-433.

[7] British Pharmacopoea (BP). Vol. 2. HM Stationery Office: London. 1993 A- 154.

[8] Adam, R.P. Identification of essential oil components by Gas Chromatography/ Mass Spectrometry. Allured Publishing Corp., 2001.Illinois, USA.

[9] Hanus L O, Rosenthal D, Rezanka T, Dembitsky V M, Moussaief A. Fast and easy GC/MS identification of myrrha resins. Pharmaceutical Chemistry Journal. 2005. 42(12):719720.

[10] Mohammed AA, Ali SI, EL-Baz FK, Hegazy AK, Kord MA. Chemical composition if essential oil and in vitro antioxidant and antimicrobial activities of crude extracts of Commiphora myrrha resin. Industrial Crops and Products. 2014. 57:10-16.

[11] Scorciapino A. Chemical composition of the essential oil and supercritical CO2 extract of Commiphora myrrha (Nees)Engl. And of Acorus calamus L. J.Agric Food Chem. 2005. 53(20):7939-43.

[12] AbdelGadir S, Ahmed IM. Commiphora myrrha and Commiphora africana essential oils. Journal of Chemical and Pharmaceutical Research. 2014. 6(7):151-156. 